\title{
Nonsurgical management of severe esophageal and gastric injury following alkali ingestion
}

\author{
Ramy D Abaskharoun MD FRCPC, William T Depew BSc MD FRCPC, Lawrence C Hookey BSc MD FRCPC
}

\begin{abstract}
RD Abaskharoun, WT Depew, LC Hookey. Nonsurgical management of severe esophageal and gastric injury following alkali ingestion. Can J Gastroenterol 2007;21(11):757-760.

The ingestion of caustic substances may result in significant gastrointestinal injury. Endoscopy can play a major role in the initial evaluation and subsequent therapy of such injuries. The case of a 50-year-old man who ingested an alkaline floor stripper is described, including the endoscopic management of esophageal and pyloric strictures, with good functional results. The role of endoscopy, steroids and acid suppression in the management of such patients is also explored.
\end{abstract}

Key Words: Caustic ingestion; Endoscopic therapy; Esophageal stricture; Pyloric stricture

7 he ingestion of corrosive substances often results in significant proximal gastrointestinal mucosal injury, occasionally perforation, and sometimes death. Despite regulations for improved labelling of such harmful substances, the rate of ingestion ranges from 5000 to 20,000 ingestions per year in the United States $(1,2)$. While the majority of these are accidental ingestions involving children, a substantial minority involve adults, often with suicidal intent (3-5). The natural history of such ingestions is dependent on numerous factors, including the quantity ingested, the $\mathrm{pH}$ of the material, the duration of exposure and its physical state (ie, solid or liquid) $(1,2,6)$. Acidic substances result in coagulative necrosis, with a protective eschar forming and limiting deep injury. In contrast, alkaline substances cause a liquefactive necrosis, with substantial submucosal vascular thrombosis, often producing transmural injury $(1,2,4,6)$.

Endoscopy plays an important role in the initial assessment of patients who have ingested a caustic material by visually defining the extent and severity of injury. Esophageal stricturing is a common complication, and antegrade dilation often provides excellent relief (7-10). Pyloric stenosis may also result from caustic injury and this complication may be amenable to endoscopic intervention $(8,11-14)$. The present report describes the care of a patient who suffered significant esophageal and gastric injury following large volume alkali ingestion. The ensuing complications, including esophageal and pyloric stricturing, were managed entirely endoscopically, with a good functional outcome.

\section{CASE PRESENTATION}

A 50-year-old male prisoner ingested $300 \mathrm{~mL}$ of liquid floor wax stripper, mixed with grape juice. The liquid's active ingredients included sodium carbonate, sodium metasilicate and sodium

\section{La prise en charge non chirurgicale d'une grave lésion œsophagienne et gastrique après l'ingestion d'un alcali}

\begin{abstract}
L'ingestion de substances caustiques peut provoquer d'importantes lésions gastro-intestinales. L'endoscopie occupe une place importante dans l'évaluation initiale et la thérapie subséquente de ces lésions. Les auteurs décrivent le cas d'un homme de 50 ans qui a ingéré un décapant à plancher alcalin, y compris la prise en charge endoscopique des constrictions œsophagiennes et pyloriques, et les bons résultats fonctionnels. Ils explorent également le rôle de l'endoscopie, des stéroïdes et de la suppression acide dans la prise en charge d'un tel patient.
\end{abstract}

hydroxide, and its $\mathrm{pH}$ was 13.4 . On the patient's arrival to the emergency room, he was experiencing difficulty swallowing his saliva. He also described oropharyngeal burning pain. He denied shortness of breath or chest pain. His vital signs were normal. The oropharynx had significant chemical burns, manifested by erythema, diffuse edema and mucosal sloughing. General physical examination was otherwise unremarkable. Laboratory tests, including complete blood count, electrolytes, creatinine levels and arterial blood gas were normal. The electrocardiogram, chest $\mathrm{x}$-ray and abdominal films were also normal. A laryngoscopy was performed, and although laryngeal erythema and edema were evident, it was determined that the patient was not at significant risk of airway compromise.

Endoscopy performed $12 \mathrm{~h}$ after ingestion revealed significant injury to the oropharynx, as well as edema and erythema in the larynx and vocal cords. The proximal esophagus sustained near-circumferential injury manifested by edema, the presence of a yellow-white coagulum and friability. The distal esophagus was more severely injured with circumferential edema, tissue sloughing and erythema (Figure 1A). Frank tissue necrosis was evident in the body and antrum of the stomach, visualized as black eschar, edema and hemorrhage (Figure 1B). The pylorus was edematous but could be intubated. The proximal duodenal cap had mild injury, but distal to this, the duodenal mucosa appeared normal.

In consultation with an esophageal surgeon, who viewed the endoscopic images of the extent of injury, surgical and nonsurgical options were discussed with the patient. In the present case, it was decided to admit the patient under close observation for any signs of deterioration. Total parenteral nutrition was initiated and the patient remained nil per os. Systemic steroids were not administered. A repeat endoscopy was performed one day after ingestion. The esophageal injury had not progressed, and

Gastrointestinal Diseases Research Unit, Division of Gastroenterology, Hotel Dieu Hospital, Queen's University, Kingston, Ontario

Correspondence: Dr Lawrence C Hookey, Sydenham 4, Hotel Dieu Hospital, 166 Brock Street, Kingston, Ontario K7L 5G2.

Telephone 613-544-3400 ext 2288, fax 613-544-3114, e-mail hookeyl@hdh.kari.net

Received for publication June 18, 2006. Accepted November 20, 2006 

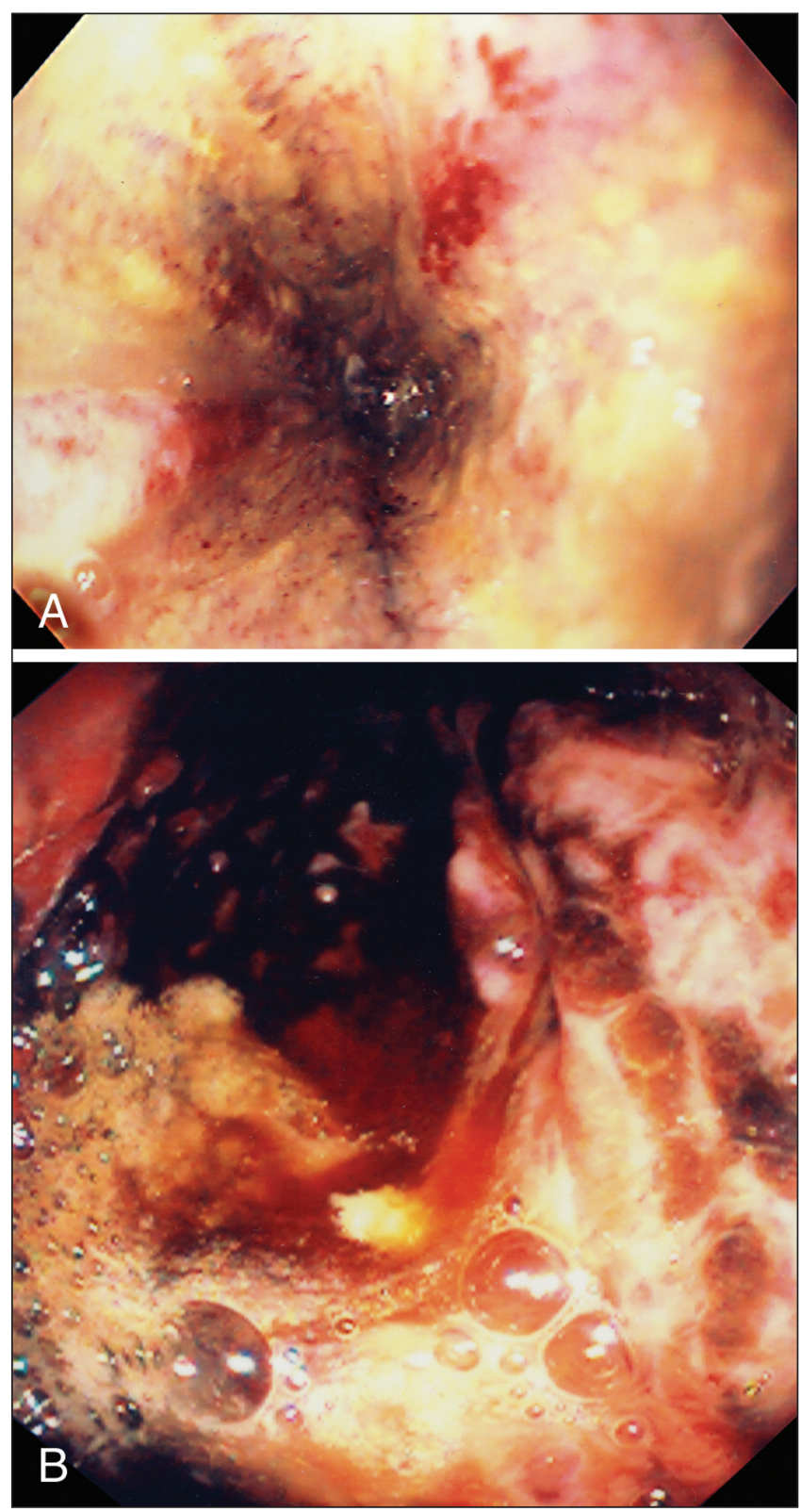

Figure 1) Photos taken during endoscopy $12 \mathrm{~h}$ following alkali ingestion, demonstrating edema, mucosal sloughing and hemorrhage of the distal esophagus (A), and severe mucosal injury with hemorrhage, edema and black eschar in the stomach (B)

the gastric body and antrum remained severely inflamed and injured. Conservative management and close observation were continued. During the next week, the patient's oropharyngeal symptoms improved and he was able to swallow secretions.

A repeat endoscopy was performed 10 days postingestion. The esophageal mucosa was healing but ulceration was still present, particularly at the site of two early strictures, $25 \mathrm{~cm}$ and $35 \mathrm{~cm}$ from the incisors (Figure 2A). The proximal stricture was noncircumferential and the adult gastroscope (diameter $9.4 \mathrm{~mm}$ ) passed through it easily. The distal stricture was circumferential and narrowed the lumen more significantly, only allowing passage of the pediatric gastroscope (diameter $8.7 \mathrm{~mm}$ ). The stomach was distorted by a contracted antrum with continued active ulceration (Figure 2B). The pylorus was patent but did have mucosal erosions and ulceration. The
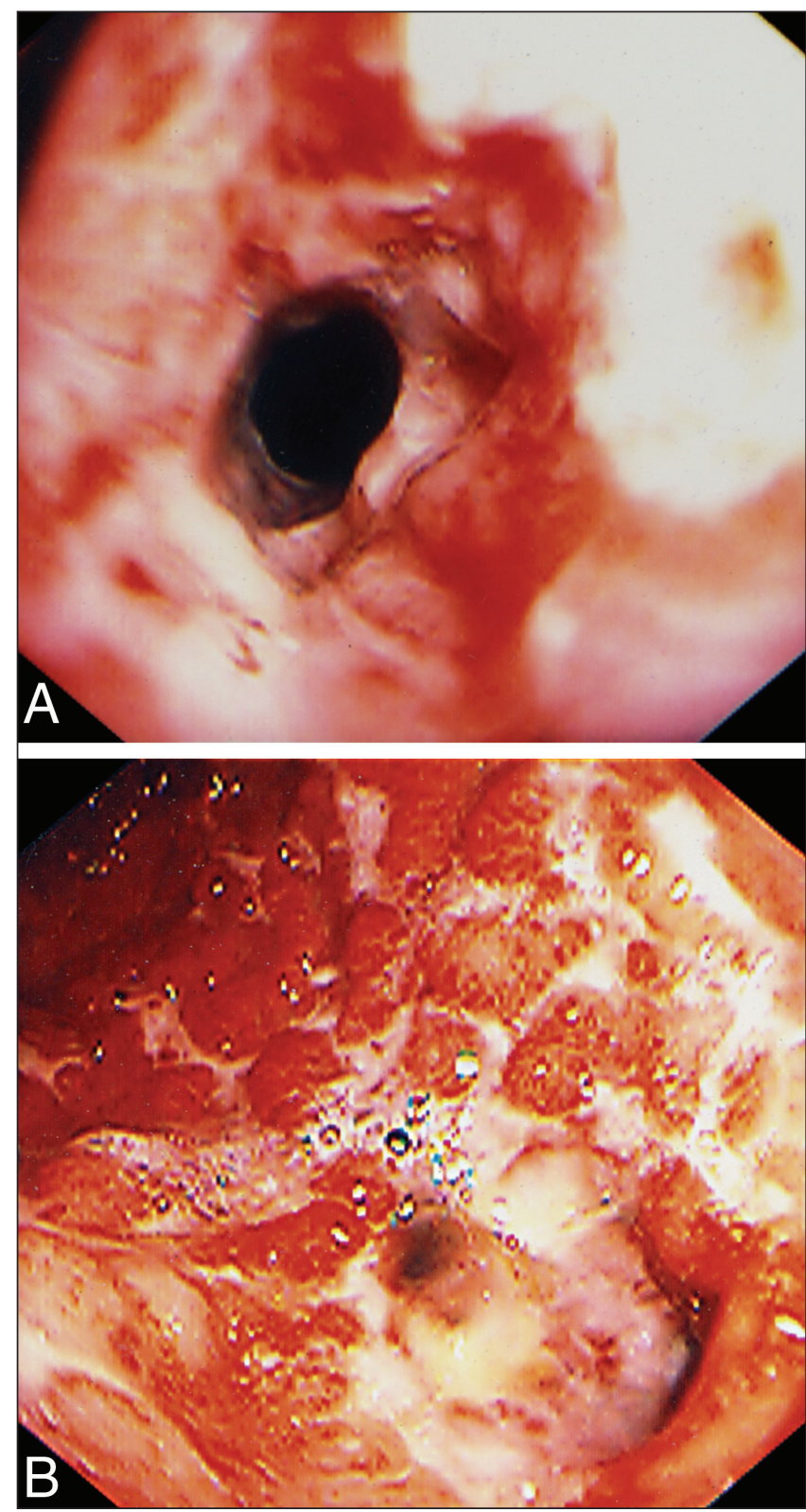

Figure 2) A Endoscopic view of an esophageal stricture and inflammation $35 \mathrm{~cm}$ from the incisors, 10 days postingestion. B Endoscopic image of a distorted antrum 10 days postingestion. Active ulceration and a narrowed but patent pylorus are demonstrated

duodenal cap had returned to normal. The esophageal strictures were serially dilated with Savary dilators over a guidewire under fluoroscopic control, starting at a diameter of $9.3 \mathrm{~mm}$ ( $28 \mathrm{Fr}$ ) to a maximum diameter of $12 \mathrm{~mm}(36 \mathrm{Fr})$. The patient was started on clear fluids and tolerated this well.

A repeat endoscopy was performed on postingestion day 17 . The distal stricture was narrowed more significantly than previously and would not allow passage of even the pediatric endoscope (diameter $8.7 \mathrm{~mm}$ ). This stricture also continued to have active ulceration. Again, under fluoroscopic control, the strictures were dilated, to a maximum diameter of $10 \mathrm{~mm}$ ( $30 \mathrm{Fr}$ ). The stomach contained copious fluid, even though the patient had nothing to drink for the preceding $16 \mathrm{~h}$. The pylorus was visualized and it continued to have active ulceration. It was strictured and would not allow passage of the 


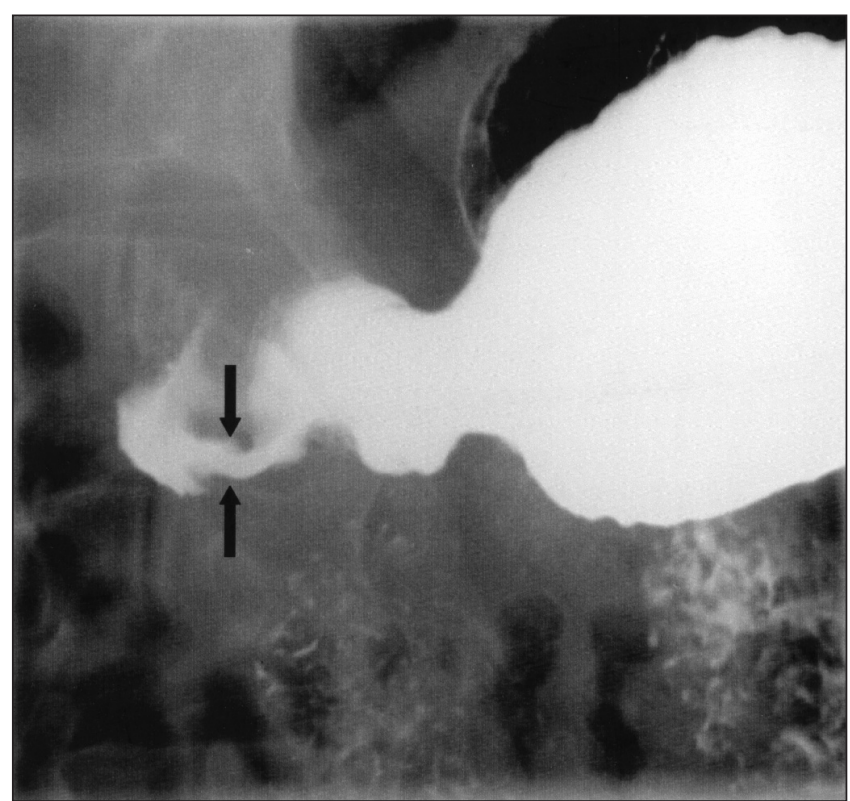

Figure 3) Barium contrast radiograph of the stomach demonstrating flow of barium through a patent pylorus (arrows) into the duodenum

pediatric endoscope. A wire was passed through the pylorus into the duodenum, under fluoroscopic control. This stricture was dilated using a $12 \mathrm{~mm}$ hydrostatic balloon (CRE, Boston Scientific, Canada), filled with saline and radio-opaque contrast dye in a one to one ratio, under 8 atm pressure for $60 \mathrm{~s}$. Under fluoroscopy, a very short balloon waist, suggesting a short pyloric stricture, was successfully dilated. The endoscope was then manoeuvred through the pylorus into the duodenum without difficulty.

Over the next three weeks, the patient underwent four further endoscopies with esophageal and pyloric dilations. After this, he denied any dysphagia. His diet was advanced to solids. There was no longer any endoscopic evidence of gastric stasis or retention. He was discharged on oral proton pump inhibitors.

Six further endoscopies were performed on him as an outpatient over the next three months. Active ulceration and inflammation at the distal esophageal stricture continued until 12 weeks after the ingestion. Up to four months after ingesting the alkali, dilations of the distal stricture were necessary, but only required one pass of an $18 \mathrm{~mm}$ (54 Fr) dilator. An upper gastrointestinal barium radiograph was performed three months postingestion. The esophagus was patent, although mildly narrowed distally. The antrum was contracted and the barium flowed easily into the duodenum (Figure 3 ). The patient was followed for 18 months after his ingestion, and experienced no dysphagia or symptoms of gastric stasis.

\section{DISCUSSION}

Alkali ingestion results in liquefactive necrosis, which is often more severe than the coagulative necrosis resulting from acid ingestion $(2,4)$. The natural history of such injuries, if perforation is avoided, is ulceration, frequently followed by strictures resulting from an intense fibrotic reaction that may occur in the weeks following ingestion (4).

Endoscopically visualized esophageal injury has been shown to be predictive of complications of caustic ingestion such as bleeding, perforation, fistula formation or death (15-18).

\section{TABLE 1}

\section{Zargar Endoscopic Classification Scheme for caustic} mucosal injury

\begin{tabular}{ll}
\hline Grade & Definition \\
\hline 0 & Normal examination \\
1 & Edema and hyperemia of the mucosa \\
$2 \mathrm{~A}$ & Superficial ulcerations, exudates, whitish membranes, blisters, \\
& erosions, hemorrhages and friability \\
$2 \mathrm{~B}$ & Grade 2A plus deep discrete or circumferential ulceration \\
$3 \mathrm{~A}$ & Small, scattered areas of necrosis \\
$3 \mathrm{~B}$ & Extensive necrosis \\
\hline
\end{tabular}

Adapted from reference 17, with permission from the American Society for Gastrointestinal Endoscopy

Two retrospective case reviews $(15,19)$ described caustic ingestion in children and adults, and showed that symptoms alone were not predictors of endoscopic injury. Furthermore, two other reports $(17,18)$ have demonstrated that the degree of oropharyngeal injury does not predict the severity of the esophagogastric injury related to the caustic ingestion. This has led to the practice of early endoscopy in the evaluation of cases of caustic ingestion such that early complications such as bleeding and perforation, or late complications of stricture formation can be anticipated. Table 1 outlines a classification system developed by Zargar et al (17). Generally, patients with grade 0,1 or $2 \mathrm{~A}$ injury escape with no sequelae. Patients with grade $2 \mathrm{~B}$ to 3 injury have a high rate of developing strictures. Patients with grade 3 injury are at risk for both systemic complications requiring intensive care unit admission and local complications of bleeding and perforation. Most deaths occur in patients with grade 3 injury (16-18).

Endoscopic antegrade dilation has been described previously in similar clinical settings (20-22). However, when such information is provided, the timing of such dilations appears to be later than performed in the present case $(23,24)$. We undertook an early dilation program due to the intense fibrotic reaction resulting in significant early stricturing. If we had elected to wait longer before dilation, it is plausible that access through the stricture in an antegrade fashion may not have been safe, or possible. The interval between dilations was decided based on literature showing that these strictures can be more difficult to manage (24), and also based on our initial experience and judgment of this particular patient's response to dilation. We believe that with strictures that still contain active inflammation and ulceration, an aggressive dilation strategy is necessary to prevent them from becoming progressively more obstructive between endoscopies.

One report (24) comparing the treatment of corrosive and peptic strictures described a high initial success rate with dilation of corrosive strictures (93.6\%). However, the authors also demonstrated increased recurrence rates $(94.4 \%$ versus $54.6 \%$, at 60 months) with corrosive strictures compared with peptic strictures, respectively. However, the majority of these recurrences occurred early (ie, within the first 18 months), and the rate of symptomatic recurrence normalized by 36 months of follow-up examinations and treatment. The observed rate of perforation for dilation of corrosive strictures was $0.8 \%$, compared with $0.3 \%$ for peptic strictures.

The present case invites discussion on steroid use to reduce the severity and persistence of esophageal and/or pyloric strictures. A controlled trial of intravenous prednisolone with 
step-down to oral prednisone in children has not shown a difference in stricture formation rates (23). Intralesional steroid injections have been described in case reports and small case series (20-22,25-30). However, this intervention is most often described in peptic strictures, with only a few cases involving caustic injury $(20,21,26,30)$. In the present case, the authors were reluctant to use intralesional steroids in the setting of such severe and persistently active mucosal injury. Only one previous report (26) commented on whether active ulceration was present when this therapy was employed. The patient described in the present report continued to have active ulceration at the distal stricture site until 12 weeks postingestion. At this point, the stricture was managed much more easily, with an increased interval between dilations. The patient was successfully managed without steroids, but the possibility exists that their use may have reduced the total number of dilations required.

In spite of obvious gastric retention, evident by copious fluid in the stomach during endoscopy, the patient never experienced symptoms of gastric stasis. The pyloric stricture responded well to balloon dilation, requiring four dilations until patency was maintained. A progression to larger balloons was not undertaken

\section{REFERENCES}

1. Loeb PM, Nunez MJ. Caustic injury to the upper gastrointestinal tract. In: Feldman M, Friedman LS, Brandt LJ, eds. Sleisenger and Fordtran's Gastrointestinal and Liver Disease: Pathophysiology, Diagnosis, Management, 7th edn. Philadelphia: Elsevier, 2002:399-407.

2. Spiegel JR SR. Caustic injuries of the esophagus. In: Castell DO, Richter JE, eds. The Esophagus, 3rd edn. Philadelphia: Lippincott Williams \& Wilkins, 1999:557-64.

3. Ashcraft KW, Padula RT. The effect of dilute corrosives on the esophagus. Pediatrics 1974;53:226-32.

4. Bosher LW Jr, Burford TH, Ackerman L. The pathology of experimentally produced lye burns and strictures of the esophagus. J Thorac Surg 1951;21:483-9.

5. Christesen HB. Caustic ingestion in adults - epidemiology and prevention. J Toxicol Clin Toxicol 1994;32:557-68.

6. Palmer ED, Major MC, Scott NM. Acute corrosive gastritis: Observations on the gastric mucosa following ingestion of concentrated hydrorchloric acid. Gastroenterology 1949;12:879-83.

7. Cello JP, Fogel RP, Boland CR. Liquid caustic ingestion. Spectrum of injury. Arch Intern Med 1980;140:501-4.

8. Ciftci AO, Senocak ME, Buyukpamukcu N, Hicsonmez A. Gastric outlet obstruction due to corrosive ingestion: Incidence and outcome. Pediatr Surg Int 1999;15:88-91.

9. Pereira-Lima JC, Ramires RP, Zamin I Jr, Cassal AP, Marroni CA, Mattos AA. Endoscopic dilation of benign esophageal strictures: Report on 1043 procedures. Am J Gastroenterol 1999;94:1497-501.

10. Rupp t, Earle D, Hawes R, et al. Randomized trial of Savary dilation with/without intralesional steroids for benign gastroesophageal reflux strictures. Gastrointest Endosc 1994;40:78. (Abst)

11. Gray HK, Holmes CL. Pyloric stenosis caused by ingestion of corrosive substances: Report of case. Surg Clin North Amer 1948;28:1041-56

12. Hogan RB, Polter DE. Nonsurgical management of lye-induced antral stricture with hydrostatic balloon dilation. Gastrointest Endosc 1986;32:228-30.

13. Maggi AL, Meeroff M. Stenosis of the stomach caused by corrosive gastritis. Gastroenterology 1953;24:573-8.

14. Treem WR, Long WR, Friedman D, Watkins JB. Successful management of an acquired gastric outlet obstruction with endoscopy guided balloon dilatation. J Pediatr Gastroenterol Nutr 1987;6:992-6

15. Poley JW, Steyerberg EW, Kuipers EJ, et al. Ingestion of acid and alkaline agents: Outcome and prognostic value of early upper endoscopy. Gastrointest Endosc 2004;60:372-7. due to the lack of symptoms and the resolution of endoscopically evident gastric retention. Such success has been reported previously, but only in a small number of cases $(20,26)$.

The role of acid suppression in this setting is unclear. Previous authors have documented initial achlorhydria postcorrosive gastric injury, sometimes with a return of normal gastric acid secretion $(6,13)$. The role of acid in the persistent ulceration in the esophagus and antrum was questioned, and the patient was empirically treated with proton pump inhibitor therapy. The gastric body was biopsied approximately 12 weeks postingestion, and parietal cells were abundant, suggesting that achlorhydria was not part of the sequelae of alkali ingestion in this case.

Although, in the past, many severe caustic ingestion injuries required laparotomy for the assessment and potential resection of necrosis, the case described was managed conservatively with observation, total parenteral nutrition and endoscopy, in consultation with an esophageal surgeon. The authors advocate an individualized approach to each patient, taking into account the extent and type of injury and the patient's clinical condition.

16. Zargar SA, Kochhar R, Nagi B, Mehta S, Mehta SK. Ingestion of corrosive acids. Spectrum of injury to upper gastrointestinal tract and natural history. Gastroenterology 1989;97:702-7.

17. Zargar SA, Kochhar R, Mehta S, Mehta SK. The role of fiberoptic endoscopy in the management of corrosive ingestion and modified endoscopic classification of burns. Gastrointest Endosc 1991;37:165-9.

18. Zargar SA, Kochhar R, Nagi B, Mehta S, Mehta SK. Ingestion of strong corrosive alkalis: Spectrum of injury to upper gastrointestinal tract and natural history. Am J Gastroenterol 1992;87:337-41

19. Gaudreault P, Parent M, McGuigan MA, Chicoine L, Lovejoy FH Jr Predictability of esophageal injury from signs and symptoms: A study of caustic ingestion in 378 children. Pediatrics 1983;71:767-70.

20. Kochhar R, Sriram PV, Ray JD, Kumar S, Nagi B, Singh K. Intralesional steroid injections for corrosive induced pyloric stenosis. Endoscopy 1998;30:734-6.

21. Lee M, Kubik CM, Polhamus CD, Brady CE III, Kadakia SC. Preliminary experience with endoscopic intralesional steroid injection therapy for refractory upper gastrointestinal strictures. Gastrointest Endosc 1995;41:598-601

22. Zein NN, Greseth JM, Perrault J. Endoscopic intralesional steroid injections in the management of refractory esophageal strictures. Gastrointest Endosc 1995;41:596-8.

23. Anderson KD, Rouse TM, Randolph JG. A controlled trial of corticosteroids in children with corrosive injury of the esophagus. N Engl J Med 1990;323:637-40.

24. Broor SL, Raju GS, Bose PP, et al. Long term results of endoscopic dilatation for corrosive oesophageal strictures. Gut 1993;34:1498-501.

25. Burdick J, Hogan WJ, Massey BT, Bohorfoursch AG, Parker H, Schmalz M. Triamcinolone injestionc decrease the need for dilation of rapidly recurring esophageal strictures. Gastrointest Endosc 1994:40:A72. (Abst)

26. Holder TM, Ashcraft KW, Leape L. The treatment of patients with esophageal strictures by local steroid injections. J Pediatr Surg 1969;4:646-53.

27. Kirsch M, Blue M, Desai RK, Sivak MV Jr. Intralesional steroid injections for peptic esophageal strictures. Gastrointest Endosc 1991;37:180-2

28. Mendelsohn HJ, Maloney WH. The treatment of benign strictures of the esophagus with cortisone injection. Ann Otol Rhinol Laryngol 1970;79:900-4.

29. Nelson RS, Hernandez AJ, Goldstein HM, Saca A. Treatment of irradiation esophagitis. Value of hydrocortisone injection. Am J Gastroenterol 1979;71:17-23.

30. Ashcraft KW, Holder TM. The experimental treatment of esophageal strictures by intralesional steroid injections. J Thorac Cardiovasc Surg 1969;58:685-91. 


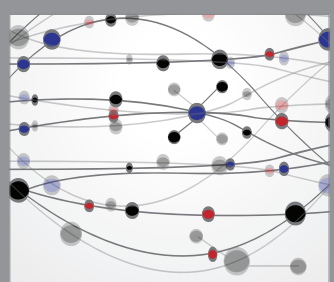

The Scientific World Journal
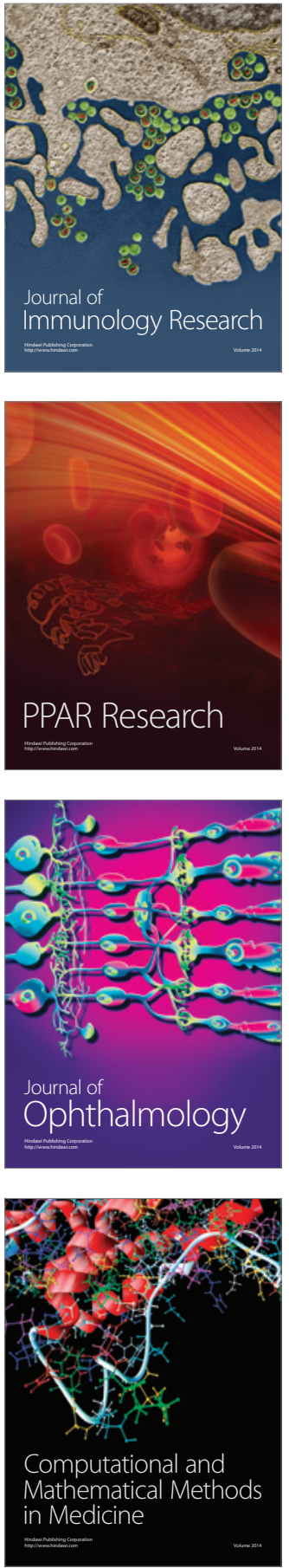

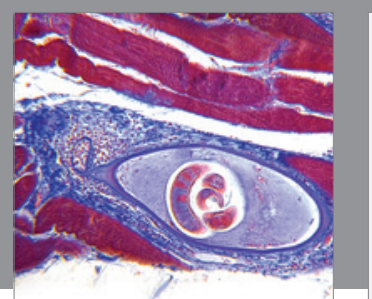

Gastroenterology Research and Practice

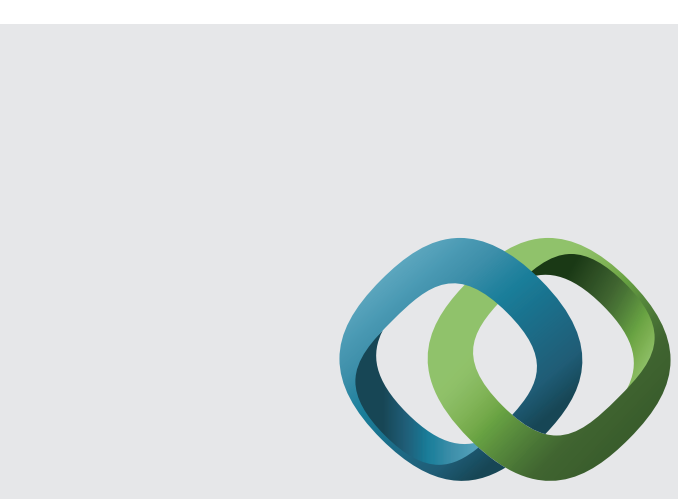

\section{Hindawi}

Submit your manuscripts at

http://www.hindawi.com
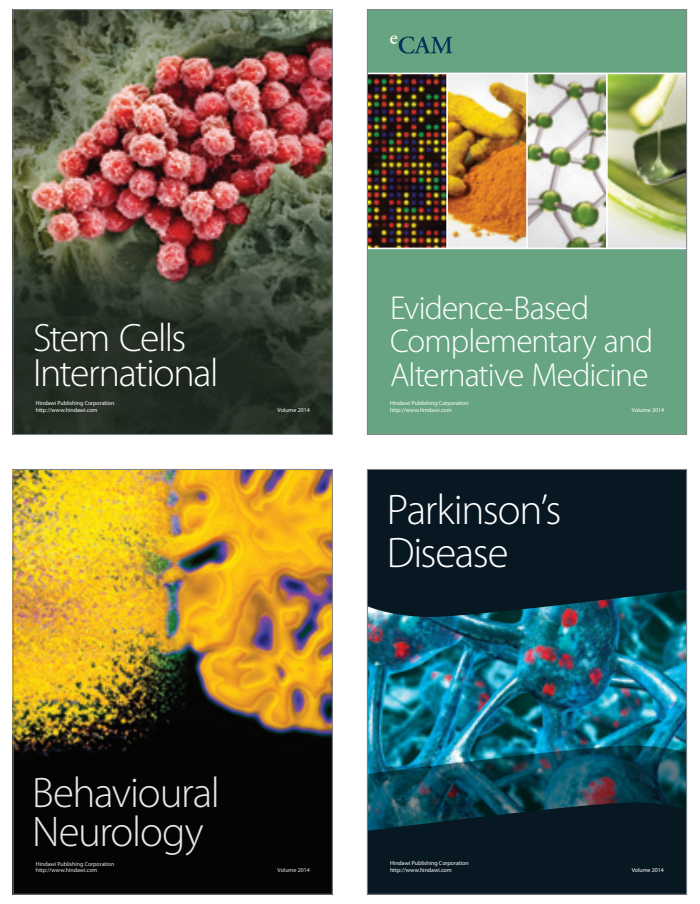
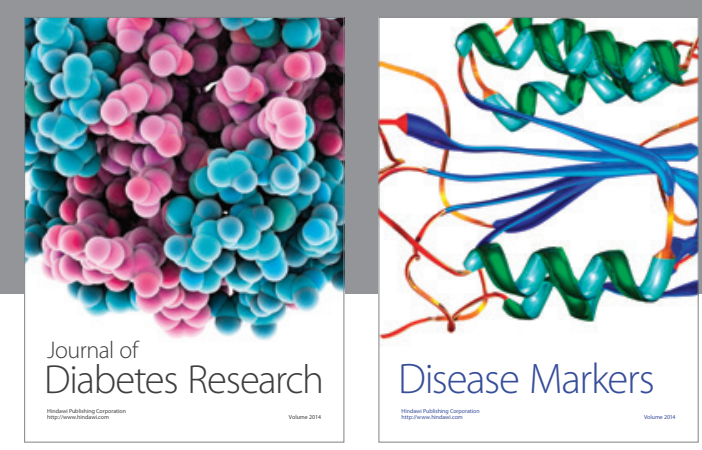

Disease Markers
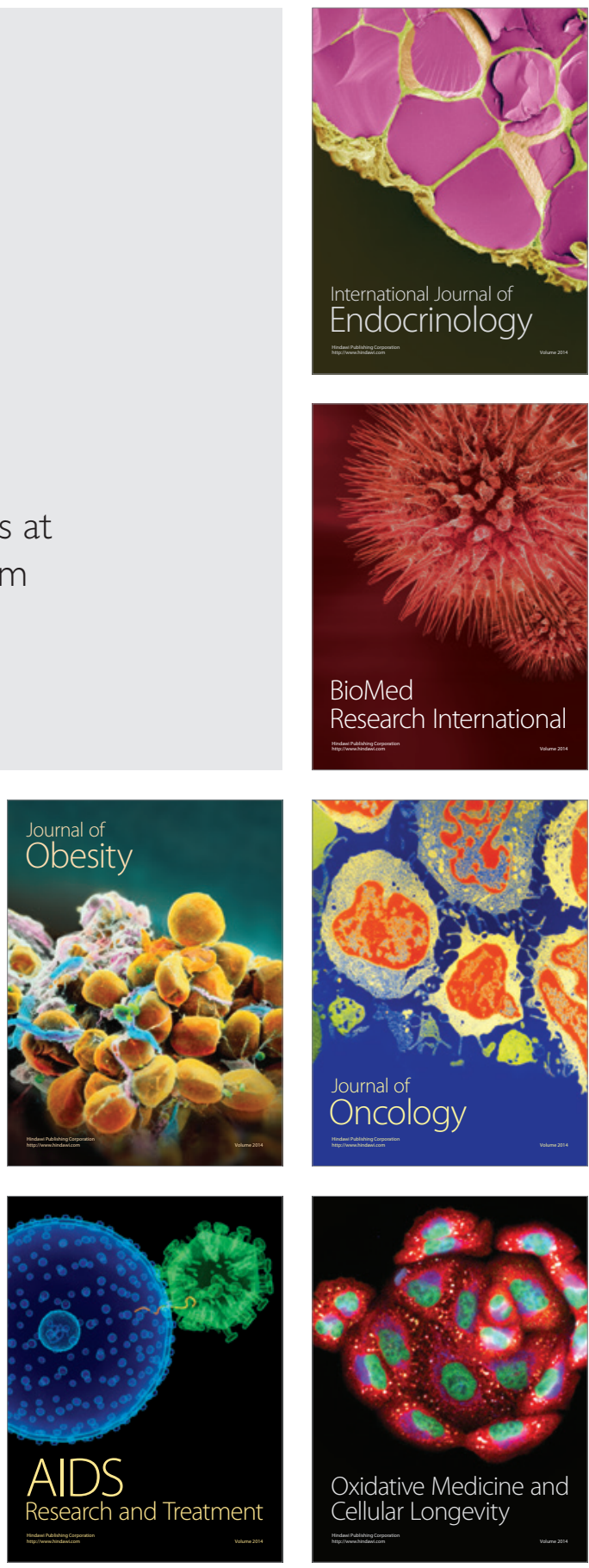